(2) Open Access Full Text Article

\title{
Metachronous contralateral pediatric inguinal hernia
}

RM Nataraja

AA Mahomed

Department of Pediatric Surgery and Urology, Royal Alexandra

Children's Hospital, Brighton, UK

Date of preparation:April 20, 2010.

Conflict of interest: None declared
This article was published in the following Dove Press journal:

Open Access Surgery

31 August 2010

Number of times this article has been viewed

Clinical question: Should routine contralateral inguinal region exploration be done to prevent a metachronous contralateral pediatric inguinal hernia?

Results: The incidence of a metachronous contralateral pediatric inguinal hernia is $6.4 \%$ in both genders. Sixteen contralateral groin explorations need to be done to prevent one metachronous contralateral pediatric inguinal hernia.

Implementation:

- Routine exploration of the asymptomatic contralateral groin is not recommended.

- Infants less than one month old with an inguinal hernia should receive immediate specialist referral.

- Older infants and children with a reducible hernia should be referred to the pediatric surgical outpatient department.

- Pediatric patients with an original left-sided hernia or who were less than six months old at the time of the first hernia repair should receive regular follow-up in the primary health care setting.

Keywords: metachronous contralateral pediatric inguinal hernia, exploration

\section{Metachronous contralateral pediatric inguinal hernia}

Definition: A metachronous contralateral inguinal hernia (MCIH) is one that develops in a previously asymptomatic groin in a pediatric patient who has undergone surgery for a unilateral inguinal hernia in the past.

Incidence: Pediatric unilateral inguinal herniotomy is one of the most common operations that pediatric surgeons perform. ${ }^{1}$ The incidence of the development of a metachronous hernia varies from 2.1 to $31 \%$ in the literature. ${ }^{2,3}$ The routine exploration of the asymptomatic side in a unilateral inguinal herniotomy is therefore controversial. Benefits include prevention of a further anesthetic in the future, any complications associated with an untreated inguinal hernia such as incarceration, and the risks associated with another procedure. The disadvantages include iatrogenic injury, testicular ascent secondary to inguinal adhesions, increased anesthetic times, and an unnecessary operation in a pediatric patient.

Economics: There is no published study that addresses the economic issues surrounding a MCIH. There may be a possible economic benefit to exploration of the contralateral asymptomatic inguinal region, because this would prevent a future admission, operation, and also a general anesthetic. 
Level of evidence: Systematic review, prospective nonrandomized trials, and retrospective cohort studies.

Search sources: Pubmed, Cochrane Library, ClinicalTrials. gov, Sciencedirect, IngentaConnect.

Outcomes: The main outcomes are:

1. Incidence of pediatric MCIH.

2. Number of contralateral explorations needed to treat to prevent one inguinal hernia.

3. Identification of at-risk groups.
Consumer summary: A MCIH is the formation of a symptomatic hernia on the opposite side to a previously repaired inguinal hernia. This new hernia is not present at the time of the original operation. There is good evidence that routine exploration of the asymptomatic side is not recommended in children.

\section{The evidence}

\section{What is the incidence of a $\mathrm{MClH}$ ?}

Systematic reviews: $\quad 2$

Prospective nonrandomized trials: $\quad 3$

Retrospective reviews: 8

There was one previous systematic review and this found that the incidence of a MCIH was $7.2 \%$ in both genders. ${ }^{4}$ The prospective trials demonstrated a large range of $\mathrm{MCIH}$ incidence $(2.3 \%-9.3 \%)$, as did the retrospective trials $(2.1 \%-7.1 \%)^{2,5-12}$ When this evidence was combined in a new systematic review, an incidence of $6.4 \%$ in 31,164 pediatric patients was revealed (Table 1).

\section{How many contralateral explorations are needed to prevent a single $\mathrm{MCIH}$ ?}

The previous systematic review found that 14 contralateral explorations were needed to prevent one metachronous hernia. The current systematic review concluded that the numbers needed to treat increased to 16 (95\% confidence interval 14.8-16.1).

\section{Are there any other factors affecting the incidence of $\mathrm{MCIH}$ ?}

The current review revealed that the gender of the patient did not influence the incidence of a MCIH (males 6.05\% versus females $6.59 \% ; P=0.202$ ). Patients younger than six months old were more likely to develop a MCIH in the future $(8.85 \%$ versus $7.12 \% ; P=0.036)$, as were patients who originally presented with a left-sided hernia $(9.6 \%$ versus $5.42 \% ; P=0.0001$ ) (Table 2).

\section{Conclusions}

It is necessary to perform 16 contralateral inguinal explorations to prevent one metachronous hernia. The incidence of a $\mathrm{MCIH}$ is $6.4 \%$. This is too low to justify routine contralateral inguinal groin exploration in children due to the potential risks of an unnecessary operation. Infants younger than six months and those with a left-sided hernia originally are at increased risk of developing a MCIH, and therefore should receive a regular review in the primary health care setting.

Table I Summary of evidence and meta-analysis

\begin{tabular}{|c|c|c|c|c|c|}
\hline & Year & Type of evidence & Patients (n) & MCIH & (\%) \\
\hline Ron et $\mathrm{al}^{4}$ & 2007 & Systematic review & 22035 & 1597 & 7.3 \\
\hline Maddox et al ${ }^{5}$ & 2007 & $\begin{array}{l}\text { Prospective } \\
\text { nonrandomized trial }\end{array}$ & 222 & 15 & 6.8 \\
\hline Kalantari et $\mathrm{al}^{6}$ & 2009 & $\begin{array}{l}\text { Prospective } \\
\text { nonrandomized trial }\end{array}$ & 301 & 28 & 9.3 \\
\hline Tsai et $\mathrm{al}^{7}$ & 2010 & $\begin{array}{l}\text { Prospective } \\
\text { nonrandomized trial }\end{array}$ & 174 & 4 & 2.3 \\
\hline Niedzielski et al ${ }^{10}$ & 1996 & Retrospective study & 5095 & 267 & 5.2 \\
\hline Marulaiah et al ${ }^{9}$ & 2006 & Retrospective study & 2124 & 44 & 2.1 \\
\hline Zamakhishardy et a ${ }^{8}$ & 2008 & Retrospective study & 266 & 19 & 7.1 \\
\hline Vogels et $\mathrm{al}^{2}$ & 2009 & Retrospective study & 280 & 14 & 5 \\
\hline Jallouli et al' ${ }^{12}$ & 2009 & Retrospective study & 164 & 5 & 3 \\
\hline Niyogi et al" & 2010 & Retrospective study & 503 & 22 & 4.4 \\
\hline Nataraja and Mahomed & 2010 & Systematic review & 31164 & 2015 & 6.4 \\
\hline
\end{tabular}

Abbreviation: $\mathrm{MCIH}$, metachronous contralateral inguinal hernia. 
Table 2 Summary of meta-analysis

\begin{tabular}{llllll}
\hline & MCIH & No MCIH & Patients $(\mathbf{n})$ & MCIH (\%) & P value \\
\hline Males & 879 & 13647 & 14526 & 6.05 & - \\
Females & 302 & 4282 & 4584 & 6.59 & 0.202 \\
$<6$ months & 97 & 999 & 1096 & 8.85 & - \\
$>6$ months & 19809 & 1519 & 21328 & 7.12 & 0.036 \\
Initial right hernia & 485 & 8471 & 8956 & 5.42 & - \\
Initial left hernia & 416 & 3915 & 4331 & 9.6 & 0.000 I \\
\hline
\end{tabular}

Abbreviation: $\mathrm{MClH}$, metachronous contralateral inguinal hernia.

\section{The practice}

\section{Potential pitfalls}

Parental education of the signs and symptoms of a MCIH should occur with advice to seek medical opinion as soon as there is a concern. Delays in specialist referral with irreducible inguinal hernias could lead to compromise of the vasculature of the incarcerated bowel and a worse outcome.

\section{Management}

Pediatric inguinal hernias when identified in the primary health care setting should be referred to a pediatric surgical center for further management.

\section{Assessment}

- There should be a swelling present in the inguinal region that may extend to the level of the scrotum.

- This should be reducible, nontender, and have no associated symptoms.

- If the swelling is tender, if erythema is present on the overlying skin, or there are associated symptoms such as vomiting, an immediate specialist referral should be made.

- In the absence of a clinical inguinal hernia, but with a strong parental history, specialist referral should be considered.

\section{Treatment}

Immediate specialist referrals:

- Infants under one month of age (even if hernia is reducible) require a same day specialist telephone referral.

- Irreducible inguinal hernias.

- Evidence of associated symptoms, such as altered feeding patterns, pain, irritability, vomiting, or abdominal distension.
Nonurgent specialist referrals:

Reducible hernias in older infants and children may be reviewed in the specialist outpatient department.

\section{Further reading}

Ron O, Eaton S, Pierro A. Systematic review of the risk of developing a metachronous contralateral inguinal hernia in children. $\mathrm{Br} J$ Surg. 2007;94:804-811.

\section{References}

1. Glick PL, Boulanger SC. Inguinal hernias and hydroceles. In: Grosfeld JL, O’Neil JA, Fonkalsrud EW Jr, Coran AG, editors. Pediatric Surgery Vol 2. 6th edition. Philadelphia, PA: Mosby-Elsevier; 2006.

2. Vogels HDE, Bruijnen CJP, Beasley SW, et al. The degree to which the size and side of an inguinal hernia is predictive of a hernia on the other side. Pediatr Surg Int. 2009;25:229-233.

3. Kiesewetter WB, Parenzan L. When should hernia in the infant be treated bilaterally? JAMA. 1959;171:287-290.

4. Ron O, Eaton S, Pierro A. Systematic review of the risk of developing a metachronous contralateral inguinal hernia in children. Br J Surg. 2007;94:804-811.

5. Maddox MM, Smith DP. A long-term prospective analysis of pediatric unilateral inguinal hernias: Should laparoscopy or anything else influence the management of the contralateral side? J Pediatr Urol. 2008;4:141-145.

6. Kalantari M, Shirgir S, Ahmadi J, et al. Inguinal hernia and occurrence on the other side: A prospective analysis in Iran. Hernia. 2009;13:41-43.

7. Tsai YC, Wu CC, Yang SSD. Open versus minilaparoscopic herniorrhaphy for children: A prospective comparative trial with midterm follow-up evaluation. Surg Endosc. 2010;24:21-24.

8. Zamakhishardy M, Ein A, Ein SH, Wlaes PW. Predictors of metachronous inguinal hernias in children. Pediatr Surg Int. 2009;25:69-71.

9. Marulaiah M, Atkinson J, Kukkady A, et al. Is contralateral exploration necessary in preterm infants with unilateral inguinal hernias? J Pediatr Surg. 2006;41:2004-2007.

10. Niedzielski J, Kobrzynska I, Loca-Kotras, et al. Is contralateral exploration in children under two years justified? Surg Child Intern. 1996;4:10-12.

11. Niyogi A, Tahim AS, Sherwood WJ, et al. A comparative study examining open inguinal herniotomy with and without hernioscopy to laparoscopic inguinal hernia repair in a paediatric population. Pediatr Surg Int. 2010;26:387-392.

12. Jallouli M, Yaich S, Dhaou MB, et al. Are there any predictive factors of metachronous inguinal hernias in children with unilateral hernia? Hernia. 2009;13:613-615. 
Open Access Surgery

\section{Publish your work in this journal}

Open Access Surgery is an international, peer-reviewed, open access journal that focuses on all aspects of surgical procedures and interventions. Patient care around the peri-operative period and patient outcomes post surgery are key topics. All grades of surgery from minor cosmetic interventions to major surgical procedures are covered. Novel techniques

Submit your manuscript here: http://www.dovepress.com/open-access-surgery-journal and the utilization of new instruments and materials, including implants and prostheses that optimize outcomes constitute major areas of interest. The manuscript management system is completely online and includes a very quick and fair peer-review system. Visit http://www.dovepress.com/ testimonials.php to read real quotes from published authors. 